\title{
Three Rationales for a Legal Right to Mental Integrity
}

\author{
Thomas Douglas and Lisa Forsberg
}

Many states recognize a legal right to bodily integrity, understood as a right against significant, nonconsensual interference with one's body. In this chapter, we offer three rationales for the recognition of an analogous legal right to mental integrity. ${ }^{1}$

\footnotetext{
${ }^{1}$ The right to bodily integrity is sometimes explicitly recognized. For example, Article 3(1) of the EU Charter of Fundamental Rights - the right to integrity of the person-states that: 'Everyone has the right to respect for his or her physical and mental integrity'. However, it is more commonly recognized implicitly. In English law, for instance, the right is implicit in the fact that nonconsensual touching of another can incur liability in either or both civil law (battery or assault) or criminal law (assault). A legal right to mental integrity could have a similar structure or could be explicitly recognized in a specific civil wrong or a criminal offence; we take no view on this here.
}

T. Douglas $(\bowtie) \cdot$ L. Forsberg

University of Oxford, Oxford, UK

T. Douglas

Jesus College, Oxford, UK

L. Forsberg

Somerville College, Oxford, UK 


\section{Introduction}

Suppose that an intruder creeps into your bedroom while you are sleeping, pierces your skin with the needle of a syringe, and injects the contents of the syringe into your muscle. And suppose that you knew nothing in advance of his plan to do this.

Clearly, the intruder has wronged you. How has he wronged you? Perhaps he has wronged you by causing you to experience some unpleasant or unwanted state. Perhaps the substance that he has injected will cause you to feel queasy, or lightheaded, or weak. But suppose that all he injected was a tiny amount of sterilized saline. And suppose this has no noticeable effect on you. Still, the intruder seems to have wronged you. How?

Perhaps he has wronged you merely by entering your bedroom without your permission. Perhaps this alone amounts to a trespass on your property or an invasion of your privacy. But this cannot be the whole story, for surely the wrong the intruder perpetrates against you is a greater wrong than the wrong that he would have committed had he entered your bedroom, but without injecting you with anything. His injecting you with a substance seems to have made a moral difference.

One plausible explanation of the difference made by his injecting you would invoke the idea of a right to bodily integrity, understood here as a right against (certain kinds of) significant, nonconsensual bodily interference. By piercing your skin with a needle, he has significantly interfered with your body, and this wrongs you by infringing your right to bodily integrity.

Though it is rarely discussed in detail or fully specified, the right to bodily integrity, as we characterized it above, is often referred to in moral, legal, and political philosophy, albeit not always by that name. ${ }^{2}$ This right is often said to be what justifies the moral requirement to obtain consent in relation to medical treatments, organ donation and sex. For instance, Stephen Wilkinson and Eve Garrard (1996, p. 338) suggest

\footnotetext{
${ }^{2}$ For example, sometimes it is instead referred to as a right against bodily trespass, especially when it is taken to be an implication of self-ownership (see e.g. Thomson, 1990, pp. 205-226; Archard, 2008, pp. 19-34).
} 
that '[o]ne way of explaining the moral significance of organ removal is by appealing to the notion of bodily integrity'. Moreover, the right is often thought to be both uncontroversial and of great importance. Again in the context of organ donation, T. M. Wilkinson (2011, p. 16) states that ' $[\mathrm{t}]$ he right to bodily integrity... is almost entirely uncontroversial and often considered of great weight'.

Similar thoughts apply at the level of law, where a legal right to bodily integrity is widely recognized. In the context of English law, Baroness Hale held in $R$ (on the application of Justin West) $v$ The Parole Board [2002] EWCA Civ 1641, that the right to bodily integrity was 'the most important of civil rights'. In Re A (Conjoined Twins) [2001] Fam 147, Walker LJ held that '[e]very human being's right to life carries with it, as an intrinsic part of it, rights of bodily integrity and autonomy-the right to have one's own body whole and intact and (on reaching an age of understanding) to take decisions about one's own body', and in Collins $v$ Wilcock [1984] 1 W.L.R. 1172, it was held that '[t]he fundamental principle, plain and incontestable, is that every person's body is inviolate. ${ }^{3}$

As with the analogous moral requirement, the legal requirement to gain the patient's valid consent to any medical procedure administered to her is often explained by reference to her right to bodily integrity or her right to be free from unlawful touching (and notably consent requirements in respect of medical interventions that do not interfere with recipients' bodily integrity are rarely discussed). We see this in medical law textbooks. For example, Emily Jackson begins her chapter on consent to medical treatment as follows: 'One of the first principles of medical law is that patients with capacity must give consent to their medical treatment. Touching a person without her consenthowever benevolently_is prima facie unlawful' (Jackson, 2019, p. 196, our emphasis). Likewise, Jonathan Herring begins his chapter on consent to medical treatment thus: 'The basic starting point is that a healthcare professional who intentionally or recklessly touches a patient without his or her consent is committing a crime (a battery) and a tort (trespass to the person and/or negligence). To be acting lawfully in touching a

${ }^{3}$ For a discussion of the right to bodily integrity in law, see Herring and Wall (2017). 
patient, the professional needs a defence' (Herring, 2018, p. 151, our emphasis). And the chapter on consent in Mason and McCall Smith's Law and Medical Ethics states that

Based on the strong moral conviction that everyone has the right of self-determination with regard to his or her body, the common law has long recognised the principle that every person has the right to have his or her bodily integrity protected against invasion by others. Only in certain narrowly defined circumstances may this integrity be compromised without the individual's consent—as where, for example, physical intrusion is involved in the carrying out of lawful arrest. In general, however, a non-consensual touching by another may-subject to the principle de minimis non curat lex - give rise to a civil action for damages or, in theory at least, constitute a criminal assault. (Laurie et al., 2019, pp. 65-66)

All of these statements characterize the requirement to obtain the patient's valid consent prior to administering medical interventions to her in terms of respect for or protection of the patient's bodily integrity.

Recently, some legal scholars have argued that, just as the law recognizes a right to bodily integrity, so too it should recognize an analogous right to mental integrity - a right that we will understand as a right against (certain kinds of) nonconsensual interference with the mind. In their seminal article, 'Crimes Against Minds', Jan Christoph Bublitz and Reinhard Merkel (2014) propose that the law recognize a right to mental self-determination which, they posit, would include a right to 'freedom from mental manipulations' (p. 58) or 'severe [mental] interferences by the state and third parties' (p. 60). ${ }^{4}$ As examples of mental interferences, they give, among others, the spiking of drinks in a restaurant with an appetite-enhancing substance (p. 58), use of subliminal imagery by an online store (p. 58), and covert modulation of brain activity using an implanted electrode (pp. 58-59).

\footnotetext{
${ }^{4}$ The right to mental self-determination would also, they think, include a 'positive dimension', which they characterize as a 'freedom to self-determine one's inner realm, e.g. the content of one's thoughts, consciousness or any other mental phenomena' (p. 60, their italics).
} 
Marcello Ienca and Roberto Andorno (2017, p. 5) also argue for the recognition of something like a right to mental integrity, in their case explicitly linking the need for this right to recent developments in the neurosciences. Here, they draw on an analogy with the way in which human rights law responded to the rapid developments in genetic technologies in the last decades of the Twentieth Century. As they note, those developments led to influential declarations concerning the human rights implications of genetic technologies ${ }^{5}$ - declarations which effectively recognized new human rights, such as the right not to know one's genetic information. ${ }^{6}$ Similar developments will, they suggest, be required in relation to neuroscience: 'the growing sensitivity and availability of neurodevices will require in the coming years the emergence of new rights or at least the further development of traditional rights to specifically address the challenges posed by neuroscience and neurotechnology' (Ienca and Andorno, 2017, p. 8). ${ }^{7}$ One new right that they propose is a right that protects individuals from the coercive and unconsented use' of emerging neurotechnologies (Ienca \& Andorno, 2017, p. 10). ${ }^{8}$ This could be understood as a variant of what we are calling the right to mental integrity-one that takes a particular stance on which nonconsensual interferences are covered by the right (namely, those that coercively employ neurotechnologies).

Finally, some have argued that what we are calling the right to mental integrity is in fact already strongly protected by international human rights law as one plank of the right to freedom of thought, though it

\footnotetext{
${ }^{5}$ Universal Declaration on the Human Genome and Human Rights (UDHGHR) 1997, and International Declaration on Human Genetic Data (IDHGD) 2003.

${ }^{6}$ UDHGHR (Art. 5(c)); IDHGD (Art. 10).

${ }^{7}$ See also the Council of Europe's Strategic Action Plan on Human Rights and Technologies in Biomedicine (2020-2025), which, at point 14, explicitly refer to neurotechnology and deep brain stimulation. Available at https://rm.coe.int/strategic-action-plan-final-e/16809c3af1. Accessed 5 June 2020.

${ }^{8}$ Ienca and Andorno understand this right as one aspect of the 'right to cognitive liberty' (with the other aspect being a right to use emerging neurotechnologies). They use the term 'right to mental integrity' to refer to a different right: the right to mental health and against mental harm (see esp. p. 18). We prefer to reserve the term 'right to mental integrity' to refer to a right against mental interference since this parallels what we think is the dominant use of the term 'right to bodily integrity'. For other authors who use the term 'right to cognitive liberty' to refer to (something close to) what we call the right to mental integrity, see Sententia (2004), Bublitz (2013), and Bublitz (2015).
} 
has not been adequately developed or enforced. Susie Alegre (2017), for instance, argues that the right to freedom of thought, which is asserted by article 9 of European Convention on Human Rights (ECHR), and article 18 of the International Covenant on Civil and Political Rights, includes a right 'not to have one's thoughts or opinions manipulated' (p. 225), where 'thought' is to be understood broadly and not limited, for example, to only serious or important beliefs (p. 224). Others have argued, more restrictedly, that the existing right to freedom of thought entails rights against 'state indoctrination' by the State or 'brainwashing' (Vermeulen \& Roosmalen, 2018, p. 738). ${ }^{9}$

The right to mental integrity has, then, made an appearance in legal scholarship. Thus far, however, the arguments for its recognition remain unclear. Though existing work has motivated the claim that we ought to accept such a right-has done much to establish the prima facie plausibility of this claim-it falls short of offering a systematic account of the rationales for it. In this chapter, we seek to make some progress towards such a systematic account by delineating and beginning to develop three distinct rationales for the recognition of a legal right to mental integrity: the appeal to intuition, the appeal to justificatory consistency, and the appeal to technological development. In doing so, we will be drawing significantly on the aforementioned work of others-indeed we limit ourselves to considering rationales that are suggested by that work-but we will also be building upon it.

Before proceeding with this task, however, we need to offer a number of qualifications.

First, a crucial distinction: the distinction between legal rights and moral rights. The abovementioned proponents of the right to mental

\footnotetext{
${ }^{9}$ European Council's handbook on Article 9 (https://www.echr.coe.int/LibraryDocs/Murdoc h2012_EN.pdf), especially p. 18. For other arguments to the effect that article 9 protects the right to mental integrity, see Bublitz (2014) and McCarthy-Jones (2019).

Article $8 \mathrm{ECHR}$ - the right to private and family life-also offers some protection for what we have called the right to mental integrity. The ECtHR held in Pretty $v$ United Kingdom that 'the concept of 'private life' is a broad term not susceptible to exhaustive definition', which 'covers the physical and psychological integrity of a person' (Pretty $v$ United Kingdom Application No 2346/02, Merits, 29 April 2002). Article 8 should be interpreted in the light of present-day conditions, thus taking into account, inter alia, technological developments and ethical issues to which they may give rise. It seems plausible, then, that article 8 protects at least some aspects of mental integrity in addition to bodily integrity.
} 
integrity appear to think of it as a legal right. For example, in discussing the parallel with genetic rights, Ienca and Andorno make clear that they are thinking of rights that might be created through international declarations, and it is very doubtful that moral rights can be created in this way. Similarly, Bublitz and Merkel defend their proposal in part by arguing that a right to mental integrity (of some kind) is already implicit in the law (in at least some jurisdictions). This would be a strange way to argue for a moral right since the law may be morally mistaken.

In what follows, we will likewise consider only the question whether we ought to recognize a legal right to mental integrity (henceforth sometimes an 'LRMI'). Some of the arguments that we give could be re-purposed as arguments for a moral right to mental integrity, but we will not pursue such re-purposing here.

Second, though our focus will be on a legal right, we will be interested in moral, and not legal, rationales for the right. A legal rationale is the sort of rationale that would matter to a court seeking to settle a case. It would establish the LRMI by appealing to existing law. It might, for example, seek to derive the LRMI from some already recognized legal right, as in Alegre's (2017) derivation from the right to freedom of thought, or to show that, as Bublitz and Merkel (2014) suggest, it is pervasively implicit in existing law. A moral rationale is, by contrast, the sort of rationale that would be of interest to the policymaker given the task of determining whether to recognize an LRMI and placed under no legal obligation to do so, or not to do so. It might, for example, seek to show that the recognition of an LRMI could be supported by plausible moral judgements, principles or theories. In this chapter, we will have nothing to say about legal rationales for the right to mental integrity, but will seek to distinguish and develop three moral rationales.

Third, a limitation on the implications of our discussion. We will, in what follows, primarily be developing — not critiquing — rationales for the LRMI. However, we take no stance on whether these rationales ultimately succeed in justifying the recognition of a LRMI. We are not at all convinced that they do, and everything we say is consistent with there in fact being a decisive case against recognizing such a right.

Fourth, a comment on the scope of the LRMI. We acknowledge that there will be immense difficulties in specifying the scope of the right, in 
part because of difficulties defining the boundaries of the mind, and in part because it is unclear exactly which kinds of nonconsensual interference with the mind would infringe the right to mental integrity. We take it to be plausible that some ways of nonconsensually influencing (and arguably interfering with) the mind will not infringe the right to mental integrity, just as there are ways of nonconsensually influencing a person's body that do not infringe their right to bodily integrity. One reason that some influences on the body fail to infringe the right to bodily integrity is that their effects on the body are not significant enough. If I wave my hand near your arm, causing the hairs on your arm to quiver, I have not infringed your right to bodily integrity, even if I do this without your consent; the effect of the influence is not significant enough. Similarly, there may be mental influences that fail to infringe the right to mental integrity because their mental impact is too insignificant. Another reason that some influences on the body fail to infringe the right to bodily integrity is that they do not employ the required means. If I tell you a disgusting story, causing you to wretch, I do not infringe your right to bodily integrity, even though causing this same bodily reaction though other means-for example, through spiking your drink-would infringe this right. The means of producing the bodily effect matter here. Similarly, there may be mental influences that fail to infringe the right to mental integrity because they do not employ the required means. Giving someone a persuasive argument might cause significant mental changes, but it is doubtful that it would infringe a person's mental integrity, even if done without consent. Exactly how significant an influence has to be to infringe the right to mental integrity, and which means of influence it must employ, are issues that we set aside for future investigation.

With these qualifications in hand, let us turn to the first argument for the recognition of a right to mental integrity: the argument from intuition. 


\section{The Appeal to Intuition}

Proponents of the LRMI frequently highlight the laxity of existing legal protections against mental interferences and point out the counterintuitive implications of this laxity. For example, Bublitz and Merkel (2014, p. 51) introduce their discussion of the LRMI as follows:

Isn't it a bit strange that unpleasant but rather trivial actions like cutting another's hair, inflicting some seconds of minor bodily pain or even firmly touching (without sexual intent) another person may constitute a criminal offense whereas deliberately causing mental suffering often falls squarely out of the purview of the criminal law?

Later, they develop the point thus:

Suppose [that] neurotools allow us to achieve what has been attemptedand, in the Maoist case, with partial success-interventions into minds changing desires and beliefs without inflicting pain, harming bodily integrity or the need to indoctrinate persons over extended periods of time. Should governments be allowed to resort to such means?-Obviously not. It appears evident that states must be barred from invading the inner sphere of persons, from accessing their thoughts, modulating their emotions or manipulating their personal preferences. At the very least, such measures are in grave need of justification. But then, there must be a right which protects individuals against such interferences. (Bublitz \& Merkel, 2014, p. 61)

What is that right? One suggestion-and the suggestion favoured by Bublitz and Merkel — is that it is the right to mental self-determination, of which the right to mental integrity, as we understand it, is one component.

We think that Bublitz and Merkel are here too quick to move from the view that it is 'obvious' and 'evident' that states should be prohibited from doing certain things to the claim that their doing those things must violate some right. It is possible to explain why states ought to be prevented from 'invading the inner sphere of persons' without appealing to (either moral or legal) rights. Perhaps states ought to be prevented 
from doing this simply because their doing so will typically cause more harm than good.

Still, we think this passage does suggest an argument in favour of recognizing an LRMI. According to this argument, we ought to recognize a legal right to mental integrity because (a) widely held moral intuitions suggest that there is a distinctive duty not to interfere with others' minds (that is, a prima facie moral duty that is distinct from the duty not to interfere with others' bodies), and (b) it would be desirable, or at least permissible, to enforce this distinctive duty through recognizing a legal right to mental integrity.

Claim (b) depends on general considerations regarding the purpose and effectiveness of legal rights that we cannot explore here. We simply take it for granted. Instead, we will focus on (a).

Which intuitions support a distinctive duty not to interfere with the minds of others? We believe that two sets of intuitions are relevant here.

First, there are intuitions to the effect that interventions that interfere with both the body and the mind often seem more seriously wrong, morally, than comparably physically invasive interventions that do not interfere with the mind. Consider the following case:

Thinking that one of her regular customers looks a little down, a wellmeaning but paternalistic barista surreptitiously slips a newly developed mild, short- and fast-acting anti-depressant into his morning coffee, with the result that the customer's mood is somewhat lifted for a few hours.

Call the intervention in this case Anti-depressant, and compare it with the following intervention, which we will call Anti-asthmatic:

Thinking that one of her regular customers looks a little wheezy, a wellmeaning but paternalistic barista surreptitiously slips a mild, short- and fast-acting anti-asthmatic medication into his morning coffee, with the result that the customer breathes somewhat more easily for a few hours.

It seems to us that Anti-depressant is, prima facie, more seriously wrong, or wrong in a different way than Anti-asthmatic, even though the two interventions seem similar with respect to the nature and degree of 
bodily interference that they involve. One plausible way to explain the difference, we think, would be to invoke a duty not to interfere with others' minds. While both Anti-depressant and Anti-asthmatic interfere with your body, and in similar ways and to similar degrees, only Antidepressant interferes with your mind. Thus, Anti-depressant infringes an additional duty, and so is more seriously wrong.

A second cluster of intuitions that support a distinctive duty not to interfere with others' minds are intuitions concerning certain physically non-invasive forms of mental interference; interventions that we would commonly refer to as 'brainwashing'. Consider, for example, the possibility that someone might hypnotize you against your will, or seek to alter your desires through subliminal imagery, or subject you to a some kind of aversion therapy in which authority figures subject you to distressing images whenever you perform some undesired behaviour. It is interventions of this sort that Bublitz and Merkel (2014, p. 61) presumably have in mind when they refer to the partial Maoist 'success' in 'changing desires and beliefs'.

It seems intuitively clear that such interventions are typically wrong. Yet we clearly cannot explain this by adverting to bodily interference, since though such forms of brainwashing must induce bodily changesthey could not otherwise affect the mind - they do not plausibly violate any duty by virtue of their bodily effects. A distinctive duty not to interfere with the minds of others could, however, explain the wrongness of brainwashing and recognizing an LRMI could help to enforce this duty.

\section{The Appeal to Justificatory Consistency}

A second point often emphasized by proponents of a right to mental integrity is that standard theoretical justifications for the right to bodily integrity appear also to support a right to mental integrity. Consider the following from Bublitz and Merkel (2014, p. 62):

In the wake of Locke, libertarians believe that persons have property rights in their body; persons literally own (the physical part of) themselves. Ownership discussions focus on the relation of persons to their 
bodies, their liberty (e.g. vis-a-vis slavery) and the fruits of their labor. But what is even more constitutive of a subject than her body is her mind. So, whoever grants self-ownership of persons over their bodies has a compelling reason to concede self- ownership over minds. ${ }^{10}$

The suggestion here, we take it, is that, if we are to recognize a legal right to bodily integrity, then we ought, on pain of inconsistency, to recognize at least a defeasible case for a legal right to mental integrity. ${ }^{11} \mathrm{We}$ ought to do this because the theoretical considerations that justify the right to bodily integrity also provide (defeasible) support to the right to mental integrity. Call this the argument from justificatory consistency.

Whether the appeal to justificatory consistency is compelling will, of course, depend on what considerations justify the right to bodily integrity. Bublitz and Merkel suggest one candidate-self-ownershipbut there are others. A full development of the argument would need to survey all plausible justifications and consider whether each supports also a right to mental integrity. We cannot pursue this approach here, but let us briefly introduce some of the most frequently mentioned justifications. These fall into broadly two categories. First, there are rights-based justifications; justifications that seek to derive the right to bodily integrity from some more fundamental right. Second, there are interest-based justifications; justifications according to which the right to bodily integrity is justified by its role in protecting some interest.

Consider first rights-based justifications. These typically appeal to one of two more fundamental rights: property rights over the self-rights of self-ownership—normally understood as analogous to property rights

\footnotetext{
${ }^{10}$ English law traditionally took the view that there are no property rights in human bodies (see e.g. $R v$ Bentham [2005] 1 WLR 1057), with the exception of cases in which the lawful exercise of work and skill has been applied to it (Doodeward $v$ Spence [1908] 6 CLR 496; $R v$ Kelly [1999] 2 WLR 384). In Yearworth $v$ North Bristol NHS Trust [2009] 3 WLR 118, the Court of Appeal held that a property right extended to one's sperm. The Human Fertilisation and Embryology Act 1990 (HEFA) as amended by HEFA 2008 regulates the storage and use of human reproductive materials by consent requirements, rather than as property, and such consent requirements provide limited guidance when conflicts over ownership arise (Evans and others $v$ Amicus Healthcare [2003] EWHC 261). Similarly, the Human Tissue Act 2004 regulates the removal, storage, use and disposal of human body parts, organs and tissue by consent, by without treating human materials as property.

${ }^{11} \mathrm{~A}$ defeasible case is a case that has some normative force, but is not necessarily decisive; it can be defeated by countervailing considerations.
} 
over external property (e.g. Thomson, 1990), and rights to personal sovereignty - understood on analogy with the rights of states over their territory (e.g. Archard, 2008; Ripstein, 2006). Both types of rights attach to the self or person (we take the two to be equivalent, and henceforth use the term 'self'), and both are normally taken to include or imply rights against interference with the self. These rights against interference with the self are in turn thought to imply rights against interference with the body since the body either is, is part of, or is closely connected to, the self.

Though discussions of self-ownership and personal sovereignty more frequently draw out implications for the body than for the mind, ${ }^{12}$ it seems clear that appeals to self-ownership or personal sovereignty will also support rights over the mind, since the mind clearly also either is, is part of, or is closely connected to, the self. ${ }^{13}$ Indeed, most currently dominant accounts of the self give the mind a more central role than the body in the self. On psychological accounts, for instance, the self is, or resides wholly in, the mind, with the body being merely a contingent receptacle for the self. So, we might think that considerations of selfownership and personal sovereignty in fact provide stronger support to a moral right to mental integrity than to a moral right to bodily integrity.

Consider next interest-based justifications. These justify the right to bodily integrity by reference to its role in protecting some interest of the right-holder. The interest most commonly invoked is the interest in autonomy, which is frequently analysed as an interest in controlling one's life, and/or in living one's life free from the control or domination of others. The thought is that the right to bodily integrity serves to safeguard our autonomy (e.g. Mill, 1859; Feinberg, 1986).

Note that the claim here need not be that every infringement of the right to bodily integrity diminishes a person's autonomy. Rather, the thought may be that, since infringements of the right to bodily integrity

\footnotetext{
12Though for rare explicit acknowledgments that rights over the self will imply rights over the mind, see, for example, Mill (1859, p. 11), who holds that '[o]ver himself, over his own body and mind, the individual is sovereign', and Lippert-Rasmussen (2018, p. 142), who characterises self-ownership as 'moral ownership of himself or herself, that is, his or her body and mind'.

${ }^{13}$ Bublitz and Merkel (2014, esp. 62, 73) make this same point.
} 
tend to diminish autonomy, recognizing a right to bodily integrity is one way (and perhaps part of the best way) to protect autonomy.

Again, it seems clear that a parallel justification would provide defeasible support to a right to mental integrity. After all, interferences with the mind can be just as threatening to autonomy as interferences with the body.

Consider the possibility of nonconsensual hypnosis, mentioned above. Nonconsensual hypnosis is a paradigmatic example both of loss of control over one's life, and subjugation to the control of another. It very plausibly produces a serious loss of autonomy on whichever of the dominant approaches to autonomy one adopts. A right to mental integrity would protect against such interferences.

\section{The Appeal to Technological Development}

A third rationale for the LRMI is suggested by the frequent reference, by proponents of the right, to recent and likely future neurotechnological developments. These developments play an especially prominent role in Ienca and Andorno's work. Following a survey of recent advances in neuroscience, they claim (2017, p. 5) that

if in the past decades neurotechnology has unlocked the human brain and made it readable under scientific lenses, the upcoming decades will see neurotechnology becoming pervasive and embedded in numerous aspects of our lives and increasingly effective in modulating the neural correlates of our psychology and behavior.

This, they suggest (p. 2) creates a possible need for new legal rights:

the possibilities opened up by neurotechnological developments and their application to various aspects of human life will force a reconceptualization of certain human rights, or even the creation of new rights.

And, on their view, one new right that might need to be created is what we are calling the legal right to mental integrity. 
Bublitz and Merkel (2014, p. 65) also emphasize the relevance of technological developments, claiming that the law must erect 'normative boundaries' around the mind now that 'neurotechnologies promise to enable us to surmount the natural boundaries of the mind (the skull) and to modulate the inward workings of the mind'.

These references to neurotechnological developments are, we think, best understood as responses to one or more of a range of potential objections to recognizing an LRMI. These objections hold that, even if there is a sense in which the mind deserves the protection of an LRMI-say, because there is a distinctive duty not to interfere with others' mindsproviding such legal protection is unnecessary or undesirable. In what follows, we survey these objections, in each case describing how an appeal to technological developments might undermine the objection.

The most straightforward reason to think that an LRMI would be unnecessary or undesirable, and the one that Bublitz and Merkel and Ienca and Andorno are most concerned to rebut, holds that recognizing an LRMI is unnecessary because the mind is in any case insusceptible to the kinds of interference that would infringe the right. Call this the insusceptibility objection.

Both Bublitz and Merkel and Ienca and Andorno acknowledge that, historically, the mind has indeed been regarded as insusceptible to mental interference, or at least, to mental interference of the kinds that seem most morally troubling: irresistible interference, or what we might call 'mind control'. Bublitz and Merkel (2014, p. 61) suggest that the right to mental integrity 'has never been considered more thoroughly because, traditionally, the mind has not been conceived as an entity vulnerable to external intrusions and hence in need of legal protection'. ${ }^{14}$ Moreover, they concede that at one point this way of thinking may have been justified; in the 1940s, 'there may have been good reasons to emphatically believe in the untouchable absoluteness of freedom of the mind' and 'the factual invincibility of the mental realm' (p. 65). Ienca and

\footnotetext{
${ }^{14}$ Bublitz and Merkel also cite evidence that delegates involved in drafting the Universal Declaration on Human Rights subscribed to this view. For example, one is reported to have held that 'It would be unnecessary to proclaim freedom of [the inner sphere] if it were never to be given an outward expression as the inner is beyond any access' (Bublitz \& Merkel, 2014, p. 64, citing Hammer, 2001, p. 34).
} 
Andorno $(2017,1)$ go further by actually endorsing the past invulnerability of the mind to external control: 'While the body can easily be subject to domination and control by others, our mind, along with our thoughts, beliefs and convictions, [have until recently been] to a large extent beyond external constraint'. Both sets of authors, however, suggest that, if the mind was ever insusceptible to irresistible interference, it is no longer so; the insusceptibility objection to recognizing an LRMI no longer holds, and the appeal to technological developments explains why.

Perhaps, however, the objection can be reintroduced in a more plausible form. It might be held that the LRMI is unnecessary not because the mind is insusceptible to interference, but because almost all forms of mental interference that might plausibly infringe the right can already be legally regulated in other more straightforward ways. For example, it might be held that the vast majority of interventions that would infringe the LRMI would also infringe the-already established-legal right to bodily integrity and could be satisfactorily regulated on that basis. True, some extreme forms of brainwashing, such as nonconsensual hypnosis, would presumably infringe a legal right to mental integrity without infringing the right to bodily integrity. But these interventions are arguably vanishingly rare. Most interferences with mental integrity involve the administration of drugs or other neurotechnologies. These interventions are somewhat physically invasive, and so can perfectly well be regulated on the basis that they infringe the right to bodily integrity. Call this the existing protection objection.

The cogency of the existing protection objection will clearly depend on which forms of mental interference, exactly, would infringe the right to mental integrity. Nonconsensual neurointerventions and the various forms of brainwashing are obvious candidates, but there is much grey area. We could legitimately wonder, for example, whether many so-called nudges might infringe the right.

Consider the famous cafeteria nudge, in which cafeteria staff place healthier foods at eye level in a cafeteria, knowing that they will then appear more salient to, and be more likely to be chosen by, cafeteria customers. Or consider the practice of serving food on smaller plates, to make a given serving size appear larger. These practices clearly involve attempts to intentionally influence a person's preferences. It would not, 
we think, be too much of a stretch to refer to them as instances of mental interference, and it thus seems possible that they would infringe a right to mental integrity, should we possess such a right.

Consider alternatively the myriad practices sometimes employed by the designers of computer games and online services for the purposes of promoting 'customer engagement'. We might think, in this connection, of the use of randomized rewards to promote addiction to computer games, or the use of bottomless newsfeeds to keep users of social media platforms online. Again, these practices might aptly be characterized as mental interference and again, and it thus seems possible that they might infringe a right to mental integrity.

If the right to mental integrity is understood very broadly, so as to include possibilities such as those we have just mentioned, then it seems clear that the existing protection objection to recognizing an LRMI fails: on a broad construal, the right to mental integrity will cover many interventions that are not physically invasive and so cannot be regulated as infringements of bodily integrity.

But suppose that the right to mental integrity should instead be understood narrowly. Suppose that it covers only those interventions that obviously involve problematic forms of mental interference. Could we then-as the existing protection objection maintains - get by with only a right to bodily integrity?

It is not clear that we could, and this is where the appeal to technological development again enters the scene. The claim might be made that we are likely, in the near future, to have at our disposal many means of mental interference that (i) would obviously infringe a right to mental integrity and (ii) cannot be adequately regulated under a right to bodily integrity. ${ }^{15}$

Indeed, some such technologies arguably already exist. Consider transcranial direct current stimulation (tDCS) and transcranial magnetic stimulation (TMS) - interventions that act on the mind by subjecting the brain to a small electric current or magnetic field. These forms of brain stimulation have been shown to be capable of modulating various aspects of mental functioning including mood, working memory,

${ }^{15}$ Bublitz and Merkel, 'Crimes Against Minds' (2014, esp. 60) make a similar point. 
cravings for addictive substances, and numerical processing ability. ${ }^{16}$ Though they typically involve devices - either electrodes or magnetsbeing placed on the scalp, it is plausible, at least for TMS, that the procedure could be performed without any touching — with the magnets held slightly above the scalp.

Consider this intervention, which we will call Nonconsensual TMS:

Your housemate, a budding neuroscientist, notices that you seem to have had a sore leg for the last few days, since completing a half-marathon. To help reduce the pain, she sneaks into your room one evening and, without your prior knowledge, subjects you to transcranial magnetic stimulation (TMS). This involves applying a magnetic field to the parts of the brain responsible for the sensation of pain using magnets placed just above the scalp. It does not involve any physical touching. The procedure succeeds in diminishing the pain that you feel over the coming days, and does not at all affect the underlying cause of the pain.

It seems clear that, in implementing Nonconsensual TMS, your housemate acts wrongly. It is plausible that the law ought to protect you against this intervention. However, it also seems doubtful that Nonconsensual $T M S$ could be adequately regulated under the head of bodily integrity, given that it involves no touching.

Similar thoughts apply to the nascent technology of optogenetics, which involves the use of light to modulate the activity of (typically genetically modified) neurones. This intervention has been shown to be capable of modulating fear (e.g. Dias et al., 2013) and erasing and reinserting memories (e.g. Nabavi et al., 2014). In cases where superficial brain areas are targeted, the light can be administered through the skull, without the need for internal light sources. Again, it seems clear that nonconsensual uses of this technology to significantly alter a person's mental states would typically be wrong. It also seems plausible that they could not be adequately regulated as infringements of the right to bodily integrity, given that shining a light through a person's skull need involve no touching.

\footnotetext{
${ }^{16}$ For a review of the effects of tDCS and other forms of non-invasive brain stimulation, see Polanía et al. (2018).
} 
We have outlined how technological developments might be invoked to diffuse two possible objections to recognizing an LRMI: the insusceptibility objection and the existing protection objection. Let us now turn to consider a third objection. It might be held that recognizing an LRMI would be undesirable because, even if the right could be precisely defined, in practice it would be too difficult to identify infringements of it, since it is difficult to identify changes to a person's mental states. As Bublitz and Merkel (2014, p. 52) note, difficulties in identifying mental changes have led to a general reluctance to legally protect the mind: "Mental states, thoughts, feelings, behavioral dispositions hidden from view in the "inner citadel" of the individual's consciousness are regarded as intangible, evanescent, too elusive for the law to handle".

Again, however, this objection may be undermined by technological developments - for example, in neuroimaging - which could allow for more accurate identification of mental alterations. As Bublitz and Merkel (2014, p. 53) write,

what especially brings the venerable issue of mental harms back on the table of legal theory is neuroscience, promising to reveal subjective states as grounded in objective facts, i.e. in events observable from the thirdperson perspective. When mental states lose their empirical intractability, the legal disregard for the mind loses its plausibility.

In this connection, it is important to note that the law does already seek to regulate some effects on the mind. For example, English criminal law accepts that actual bodily harm (ABH) for the purposes of the Offences Against the Person Act 1861 comprises psychiatric or psychological harm in addition to harm directly inflicted on the body. The Crown Prosecution Service advises that '[p]sychological harm that involves more than mere emotions such as fear, distress or panic can amount to $\mathrm{ABH}$ ', but that 'psychological injury not amounting to recognizable psychiatric illness does not fall within the ambit of bodily harm for the purposes of the 1861 Act'. ${ }^{17}$ In order for psychiatric or psychological injury to

\footnotetext{
${ }^{17}$ Crown Prosecution Service, Offences against the Person, incorporating the Charging Standard, available at https:/www.cps.gov.uk/legal-guidance/offences-against-person-incorporatingcharging-standard, updated 6 January 2020. $R v$ Chan-Fook [1993] EWCA Crim 1; $R v$ Ireland
} 
amount to $\mathrm{ABH}$, it must be supported by appropriate medical expert evidence.

An LRMI would, we suppose, cover a much broader range of mental alterations than existing protections against $\mathrm{ABH}$. For example, just as the right to bodily integrity protects against even non-harmful forms of bodily interference, we might expect a right to mental integrity to protect against non-harmful forms of mental interference. Many such interferences would presumably involve much more subtle mental alterations than those which constitute psychiatric or psychological injury-alterations for which it would historically have been difficult to provide reliable, objective evidence. However, new technologies may help to provide reliable, objective evidence of a broader range of different kinds of mental alteration, including many that would like beyond the scope of $\mathrm{ABH} .{ }^{18}$

\section{Concluding Thoughts}

We have identified and outlined three distinct rationales for recognizing a legal right to mental integrity, drawing on comments previously made by others to motivate the recognition of this right: the appeal to intuition, the appeal to justificatory consistency, and the appeal to technological development.

Each of these rationales is open to question. For example, one could attempt to rebut the appeal to intuition by maintaining that there are better ways to legally enforce the distinctive duty not to interfere with others' minds than by recognizing an LRMI, one could attempt to rebut the appeal to justificatory consistency by denying that we ought to recognize a right to bodily integrity, and one could attempt to rebut all three appeals by maintaining that enforcing an LRMI would-even given technological developments-be too costly. Nevertheless, we think that each of these candidate rationales has some plausibility and warrants

[1998] CA 147; Director of Public Prosecutions v Smith [2006] EWCA 94; $R v D$ [2006] EWCA Crim 1139.

${ }^{18}$ For criticisms of the law relating to psychiatric injury, see e.g. Teff (2009) and Ahuja (2015). 
further scrutiny. We hope that by outlining and distinguishing them, we will encourage such scrutiny.

\section{References}

Ahuja, J. (2015). Liability for psychological and psychiatric harm: The road to recovery. Medical Law Review, 23(1), 27-52.

Alegre, S. (2017). Rethinking freedom of thought for the 21st century. European Human Rights Law Review, 3, 221-233.

Archard, D. (2008). Informed consent: Autonomy and self-ownership. Journal of Applied Philosophy, 25(1), 19-34. https://doi.org/10.1111/j.1468-5930. 2008.00394.x.

Bublitz, J. C. (2013). My mind is mine!? Cognitive liberty as a legal concept. In E. Hildt \& A. Franke (Eds.), Cognitive enhancement. Trends in augmentation of human performance (Vol. 1). Dordrecht: Springer.

Bublitz, C. (2014). Freedom of thought in the Age of neuroscience. Archiv Für Rechts- Und Sozialphilosophie, 100, 1-25.

Bublitz, J. C. (2015). Cognitive liberty or the international human right to freedom of thought. In J. Clausen \& N. Levy (Eds.), Handbook of neuroethics. Dordrecht: Springer.

Bublitz, J. C., \& Merkel, R. (2014). Crimes against minds: On mental manipulations, harms and a human right to mental self-determination. Criminal Law and Philosophy, 8(1), 51-77. https://doi.org/10.1007/s11572012-9172-y.

Dias, B. G., et al. (2013). Towards new approaches to disorders of fear and anxiety. Current Opinion in Neurobiology, 23(3), 346-352.

Feinberg, J. (1986). Harm to self. Oxford: Oxford University Press.

Hammer, L. (2001). The international human right to freedom of conscience. Dartmouth: Ashgate.

Herring, J. (2018). Medical law and ethics (7th ed.). Oxford: Oxford University Press.

Herring, J., \& Wall, J. (2017). The nature and significance of the right to bodily integrity. Cambridge Law Journal, 76(3), 566-588. https://doi.org/ $10.1017 / S 0008197317000605$. 
Ienca, M., \& Andorno, R. (2017). Towards new human rights in the age of neuroscience and neurotechnology. Life Sciences, Society and Policy, 13, 5. https://doi.org/10.1186/s40504-017-0050-1.

Jackson, E. (2019). Medical law: Cases, text and material (5th ed.). Oxford: Oxford University Press.

Laurie, G., Harmon, S., \& Dove, E. (2019). Mason and McCall Smith's Law and medical ethics. Oxford: Oxford University Press.

Lippert-Rasmussen, K. (2018). The self-ownership trilemma, extended minds, and neurointerventions. In D. Birks \& T. Douglas (Eds.), Treatment for crime: Philosophical essays on neurointerventions in criminal justice. Oxford: Oxford University Press.

McCarthy-Jones, S. (2019). The autonomous mind: The right to freedom of thought in the twenty-first century. Frontiers in Artificial Intelligence, 2(19), $1-17$.

Mill, J. S. (1975) [1859]. On liberty (D. Spitz, Ed.). Toronto: W. W. Norton.

Nabavi, S., et al. (2014). Engineering a memory with LTD and LTP. Nature, 511(7509), 348-352.

Polanía, R., Nitsche, M. A., \& Ruff, C. C. (2018). Studying and modifying brain function with non-invasive brain stimulation. Nature Neuroscience, 21, 174-187.

Ripstein, A. (2006). Beyond the harm principle. Philosophy \& Public Affairs, 34(3), 215-245.

Sententia, W. (2004). Neuroethical considerations: Cognitive liberty and converging technologies for improving human cognition. Annals of the New York Academy of Sciences, 1013(1), 221-228.

Teff, H. (2009). Causing psychiatric and emotional harm: Reshaping the boundaries of legal liability. Oxford: Hart Publishing.

Thomson, J. J. (1990). The realm of rights. Cambridge, MA: Harvard University Press.

Vermeulen, B., \& Roosmalen, M. (2018). Freedom of thought, conscience and religion. In P. van Dijk, F. van Hoof, A. van Rijn, \& L. Zwaak (Eds.), Theory and practice of the European convention on human rights (5th ed.). Cambridge: Intersensia.

Wilkinson, S., \& Garrard, E. (1996). Bodily integrity and the sale of human organs. Journal of Medical Ethics, 22(6), 334-339.

Wilkinson, T. M. (2011). Ethics and the acquisition of organs. Oxford: Oxford University Press. 
Thomas Douglas is Professor of Applied Philosophy at the Oxford Uehiro Centre for Practical Ethics, where he is Director of Research and Development. He is also a Senior Research Fellow at Jesus College, Editor of the Journal of Practical Ethics, and Principal Investigator on the project 'Protecting Minds: The Right to Mental Integrity and the Ethics of Arational Influence', funded by a Consolidator Award from the European Research Council. His research lies mainly in practical and normative ethics and currently focuses on the ethics of predicting and influencing behaviour.

Dr. Lisa Forsberg is a British Academy Postdoctoral Fellow in the Faculty of Law, and (in Philosophy) at Somerville College and the Oxford Uehiro Centre for Practical Ethics. Her main research interests lie in normative and practical ethics, and in the philosophy of medical and criminal law. Her postdoctoral project, 'Changing One's Mind: Neurointerventions, Autonomy, and the Law on Consent', is on medical consent and examines the extent to which English law on consent sufficiently protects morally salient patient interests.

This chapter is licensed under the terms of the Creative Commons Attribution 4.0 International License (http://creativecommons.org/licenses/by/4.0/), which permits use, sharing, adaptation, distribution and reproduction in any medium or format, as long as you give appropriate credit to the original author(s) and the source, provide a link to the Creative Commons license and indicate if changes were made.

The images or other third party material in this chapter are included in the chapter's Creative Commons license, unless indicated otherwise in a credit line to the material. If material is not included in the chapter's Creative Commons license and your intended use is not permitted by statutory regulation or exceeds the permitted use, you will need to obtain permission directly from the copyright holder.

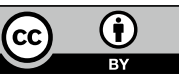

